\title{
Um estudo bibliográfico sobre o planejamento estratégico em micro e pequenas empresas
}

O presente estudo tem como objetivo analisar o quanto o planejamento estratégico é utilizado em micro e pequenas empresas e mostrar como a ferramenta planejamento estratégico é importante para um empreendimento seja de grande ou pequeno porte. A pesquisa foi realizada com base nas plataformas de artigos periódicos Capes e Anpad. O estudo é de natureza básica, exploratória, e sua abordagem é qualitativa. Esta pesquisa busca mostrar a importância do planejamento estratégico e espera-se servir de apoio para aqueles que buscam entender o planejamento estratégico e para quem pretende abrir seu próprio negócio. Para o âmbito acadêmico proporciona conhecimento e informações para os futuros profissionais, para o âmbito social esclarece dúvidas e mostrar as pessoas que 0 planejamento estratégico pode ser um diferencial para as empresas, principalmente as de pequeno porte.

Palavras-chave: Planejamento; Planejamento estratégico; Micro e pequenas empresas.

\section{A bibliographic study on strategic planning in micro and small business}

\begin{abstract}
This study aims to analyze how strategic planning is used in micro and small companies and show how the strategic planning tool is important for a large or small enterprise. The research was conducted based on the Capes and Anpad periodical article platforms. The study is basic in nature, exploratory, and its approach is qualitative. This research seeks to show the importance of strategic planning and is expected to support those seeking to understand strategic planning and those who want to start their own business. For the academic environment, it provides knowledge and information for future professionals, for the social environment it clarifies doubts and shows people that strategic planning can be a differential for companies, especially small ones.
\end{abstract}

Keywords: Planning; Strategic planning; Micro and small businesses.

Topic: Planejamento, Estratégia e Competitividade

Reviewed anonymously in the process of blind peer.

Sandy Wene Ferreira Farias

Faculdade Vale do Salgado, Brasil

sandy_wenne02@hotmail.com

Antonio Raniel Silva Lima

Faculdade Vale do Salgado, Brasil

http://lattes.cnpq.br/3467170484393980

http://orcid.org/0000-0002-9563-2160

tomraniel@outlook.com
Received: 10/01/2019

Approved: 21/04/2019
Referencing this:

FARIAS, S. W. F.; LIMA, A. R. S.. Um estudo bibliográfico sobre o planejamento estratégico em micro e pequenas empresas. Entrepreneurship, v.4, n.1, p.34-41, 2020. DOI: http://doi.org/10.6008/CBPC2595-4318.2020.001.0005 


\section{INTRODUÇÃO}

Este estudo busca analisar o quão é importante o planejamento estratégico para um micro negócio e um pequeno empreendimento. Ser um empreendedor é buscar através de seu próprio esforço e conhecimento, a sua liberdade financeira, melhora na qualidade de vida, e proporcionar as outras pessoas oportunidades de emprego, gerar renda para os demais e movimentar a economia do lugar ao qual a pessoa faz morada.

Porém em muitos casos ocorre logo que de imediato a declaração de falência do negócio e isso se dar a falta do planejamento estratégico, definição de metas e da não construção estratégica de como cada passo deve ser feito para que o negócio tenha sustentabilidade. É o planejamento estratégico que mostra como o negócio pode dar certo.

Qualquer empreendimento seja ele de grande, médio ou pequeno porte necessita de um planejamento estratégico eficiente para se consolidar e conseguir seu espaço o ramo de atuação destacandose dos concorrentes. Como o planejamento estratégico pode auxiliar os gestores das MPE's é o principal objetivo desta pesquisa.

\section{REVISÃO TEÓRICA}

\section{Planejamento}

$\mathrm{O}$ ato de planejar envolve especificamente pensar sobre aquilo que existe, pensar sobre o que se pode alcançar e principalmente quais serão os meios utilizados para realizar tais fins (OLIVEIRA et al., 2011). Planejar em si, exige determinados aspectos simples e básicos a serem levados em consideração, primeiramente, é o conhecimento acerca da realidade daquilo que deseja ser planejamento, levando em conta as necessidades que devem ser discutidas e trabalhadas, sendo estas evidenciadas pelo planejador para assim trocar suas finalidades, suas metas e objetivos. Outros aspectos é a definição de objetivos claros e também significativos, onde estes compõem a parte crucial do planejamento, pois são eles os responsáveis por direcionar e determinar as etapas do planejamento (OLIVEIRA et al., 2011).

Chiavenato (2003), diz que o planejamento é a função administrativa que é responsável por definir os objetivos e decidir quais os recursos e as atividades realizadas para alcança-los de maneira correta. É no processo de planejamento que são definidos os objetivos, fazer uma análise detalhada do que precisa ser feito para alcançar os objetivos e fazer projeções a longo prazo usando as condições futuras das organizações. (CHIAVENATO, 2004).

Segundo Kotler (2000), o planejamento é o que motiva e encoraja a administração a pensar de maneira sistemática no que acontece no presente e no que acontecerá futuramente em uma organização. $O$ planejamento é a força da empresa, onde com eles são definidos os objetivos e as políticas das organizações, bem como, auxilia na coordenação de seus recursos e oferece padrões de desempenho para o controle da empresa.

Para Maximiano (2008), planejar a atividade que tem como função definir um futuro desejado e 
também é essencial para o processo de tomada de decisões, onde este é caracterizado por haver a existência de alternativas. Oliveira et al. (2011), define o planejamento como o uso de técnicas, atividades administrativas e processos que proporcionam avaliar as implicações futuras de decisões presente, tendo em vista os objetivos empresariais auxiliando a tomada de decisão no futuro de maneira rápida, coerente e eficiente.

\section{Estratégia}

Para Chiavenato (2004), estratégia no âmbito empresarial é a mobilização dos recursos da empresa de maneira global visando atingir as metas e objetivos a longo prazo. A estratégia é o caminho. Trata-se da ação em si, da ação planejada, formulada e adequada para alcançar as metas e os objetivos estabelecidos, de forma diferenciada, garantindo o melhor posicionamento da empresa. É a estratégia que exerce o papel de 'passos' para a organização onde somente assim é possível guiar os gestores em suas decisões (OLIVEIRA et al., 2011).

Segundo Chiavenato (2010) a estratégia é considerada uma arte e uma ciência por se tratar de uma reflexão e ação, ou seja, o agir e não somente o pensar em agir. Ela é considerada uma escolha onde toda a organização é envolvida, além de selecionar as vaias hipóteses existentes, para enfim decidir qual a melhor opção para a organização de acordo com o ambiente interno e externo da mesma.

Com a estratégia é possível ao gestor delimitar o curso da ação escolhida pelo mesmo a partir desta premissa pode-se prever um futuro que ofereça ganhos e vantagens em relação a atual situação de cada organização (CHIAVENATO, 2010). Cavalcante (2008) diz que as estratégias são os resultados de um processo controlado, bem elaborado e consciente de um planejamento formal, dividido em etapas. Ressalta ainda que surgem prontas e as características como sendo explicitadas para que as estratégias possam ser implementadas por meio da atenção cuidadosa quanto a objetivos e orçamentos.

Para o âmbito organizacional a estratégia significa o comportamento global da organização em relação ao ambiente que o cerca. A estratégia é praticamente uma resposta organizacional no que diz respeito ao ambiente. A estratégia necessita de implementação, e esta é a etapa principal, onde para ser bemsucedida, ela precisa ser colocada em ação por todos os indivíduos da organização, todos os dias e em todas as ações.

\section{Conceito e caracterização do planejamento estratégico}

Nos dias atuais, as mudanças, se tornaram cada vez mais complexas, fazendo com que o mundo organizacional e empresarial tomasse duas direções: seguir as transformações e acompanhar as tendências de mercado ou prever as mudanças e antecipar-se a elas. Mintzberg et al. (2001) diz que ao analisar a estratégia como um plano surge a elaboração de um planejamento seguindo uma linha de decisões estruturadas em um determinado processo. Sendo assim o planejamento estratégico pode ser conceituado como um sistema interligado formado por decisões, gerando dados e informações para ajudar os gestores a raciocinar estrategicamente, contribuindo para articulação de estratégias e visões do futuro empresarial. 
Diante do cenário de diversas transformações, o plano estratégico se torna uma ferramenta de grande importância para a empresa porque a faz olhar diretamente para o futuro, prevenindo as ameaças, identificando as oportunidades e se mantendo ativa as constantes mudanças do mercado. Maximiano (2008), destaca que para que a empresa tenha um planejamento estratégico qualidade é necessário realizar uma avaliação que envolve diversos componentes, dentre os quais estão: a missão, a vocação e as competências da empresa, o desempenho da organização como um todo, os desafios bem como as oportunidades do ambiente organizacional, além dos seus pontos fortes e fracos do sistema interno da empresa.

O planejamento estratégico determina para o gestor ou empreendedor o caminho atingir tais objetivos com foco no futuro empresarial (AMBROSIO, 2007). Para Kotler (2000) o plano estratégico, consiste em todo um processo general que mantém o equilíbrio entre as metas estabelecidas, as habilidades adotadas, os recursos e também as oportunidades que surgirão através de um mercado que está em mudança constante. É através do planejamento estratégico que a organização pode através de seus líderes, gestores, traçar soluções, para os problemas da empresa, criar novas maneiras de gerar lucro e buscar melhorar naquilo que a empresa necessita mudar.

O planejamento estratégico consiste na formulação de estratégias, de ações e recursos estratégicos e também da escolha da ação mais eficiente de acordo com a situação de momento para com a organização. O plano estratégico define as características, mostra as implicações futuras das decisões do presente da empresa (PEREIRA, 2008). O planejamento estratégico está relacionado principalmente a ferramenta SWOT, que consiste em identificar os pontos fortes, pontos fracos, os 4 pilares fundamentais que compõem o planejamento estratégico.

A matriz SWOT e FOFA, é utilizada pelas organizações para avaliar e entender os ambientes interno e externo da empresa, com isso, é possível a empresa se alto conhecer, compreender o que torna sua estrutura bem-sucedida, e que a mantém em um bom posicionamento diante das empresas concorrentes. Além disso, a FOFA permite identificar onde a empresa pode melhorar, onde ela deve se aperfeiçoar e corrigir o que está sendo feito de errado, podendo eliminar o que a impede de progredir e aproveitar as oportunidades de crescimento que podem surgir (SILVEIRA, 2001).

O planejamento estratégico é constituído por 4 etapas: o diagnóstico estratégico, a missão da empresa, os instrumentos prescritivos e quantitativos, e também o controle e avaliação. O diagnóstico estratégico é dividido em 5 etapas: Identificação da visão; Identificação de valores; Análise externa; Análise interna; Análise dos concorrentes (OLIVEIRA et al., 2011).

A segunda etapa do planejamento estratégico é a missão. Para Dornelas (2010), a missão deve demonstrar a razão de ser da empresa, o que ela representa e o que ela faz. Oliveira et al. (2011), diz que os instrumentos prescritivos e quantitativos expressa onde a empresa quer chegar e como a empresa fará para alcançar suas metas. Os instrumentos quantitativos se relacionam com a parte orçamentaria da empresa lidando especificamente aos recursos financeiros que a organização possui (REBOUÇAS, 2005).

Já a parte do controle e avaliação, de acordo com Rebouças (2005), constitui a última etapa do planejamento estratégico, onde a empresa realiza uma retrospectiva, e se auto avalia quanto aos objetivos e 
metas traçados. O controle pode ser definido como a ação que assegura a realização dos objetivos, desafios, metas, estratégias e projetos estabelecidos pela organização.

\section{Micro e pequenas empresas}

A definição correta para micro e pequenas empresas caracteriza-se como invariável, pois vários critérios são levados em consideração quando parte para esse lado de conceituação. Suas principais características de definição se dar devido a uma variedade de fatores considerados principalmente na pratica, como instituições financeiras oficiais, órgãos representativos do setor, e ainda através do faturamento anual, do número de pessoas ocupadas.

A partir da década de 80, com a economia decrescendo e as oportunidades de emprego diminuindo, os pequenos negócios tornaram-se uma oportunidade e um meio de ocupação de mão-de-obra excedente, surgindo assim os primeiros empreendimentos incentivando a abertura de microempresas na economia. As micro e pequenas empresas exercem um papel importante e de destaque no país. No ano de 2001, as pequenas empresas representavam 23,2\%, do PIB - Produto Interno Bruto. No ano de 2011, este índice cresceu e atingiu 27\%. Com isto, as MPE's tornam-se fundamental para o desenvolvimento econômico do país.

Os diferentes tipos de empreendimentos, seja (micro, pequena, média e grande empresa), traz dificuldades quanto a concordância de pesquisadores e demais profissionais em relação aos critérios e classificação da parte das empresas. Entretanto, apenas alguns critérios são realmente usados nos diversos segmentos ou setores.

É preciso ressaltar a importância das MPE's, elas são responsáveis por proporcionar a sustentação da economia brasileira, seja pela sua geração de empregos ou pelo significativo número de empreendimentos desconcentrados geograficamente. Auxiliam ainda com atuação complementar aos empreendimentos de grande porte, e ainda possuem a capacidade de criar uma classe empresarial nacional, contribuindo com a participação do setor privado para a economia do país. O trabalho que as MPE's exercem veem se destacando e em muitos países, está sendo avaliado investir nestes empreendimentos devido gerar novas oportunidades de emprego e de produção industrial (SILVA, 2004).

\section{METODOLOGIA}

Este estudo caracteriza-se de natureza básica, onde buscará mostrar um melhor entendimento para aqueles que almejam ampliar seus conhecimentos a respeito do assunto abordado pela mesma, sem nenhum tipo de preocupação com seus benefícios Gil (2010). O objetivo adotado é o exploratório que proporcionará um entendimento mais simples, possibilitando assim maior familiaridade ao problema que será abordado na pesquisa (GIL, 2010). Quanto sua à abordagem é qualitativa, onde está trabalha seguindo um universo de motivos, valores, crenças que faz relação ao universo mais profundo das coisas, dos processos e fenômenos (MINAYO, 2001). Os procedimentos que serão usados na pesquisa caracterizam-se como bibliográficos, pois as informações da pesquisa serão de fontes de livros, artigos científicos e tem como finalidade fazer com que 
o leitor esteja ligado diretamente com tudo o que for escrito ou até mesmo dito na pesquisa de campo (MARCONI et al., 2010).

Foram adotados artigos que serviram de base para este estudo, artigos estes encontrados nos sites Periódicos Capes e Anped, onde estes forneceram as principais informações para a construção deste estudo, além também da contribuição de outros artigos, livros e sites da plataforma Google Acadêmico. Através da seleção de artigos buscou-se adotar aqueles que realmente tratavam do assunto de forma clara e direta. Quanto a organização e análise dos dados serão utilizados o referencial teórico e a análise dos resultados sobre leituras e obras referentes ao objeto de estudo proposto.

\section{RESULTADOS E DISCUSSÃO}

O planejamento em si é uma ferramenta usada por todo e qualquer empreendedor, e até mesmo pelas pessoas para realizar suas atividades diárias. O planejamento é logicamente usado por grandes e pequenas empresas, porém, neste sentido o que ganha destaque é o planejamento estratégico que surge como um meio projetado e determinado para guiar o gestor e sua equipe no desempenho das funcionalidades, bem como, na busca por resultados positivos, principalmente na área financeira da empresa. Diante disto, cabe destacar as diferenças simplórias que existem entre um grande empreendimento e as MPE's. Para Souza et al. (2007) as empresas de grande porte possui benefícios e vantagem sob as MPE's isso devido, as grandes empresas ter qualidade na estrutura, e dos profissionais para dar suporte, e também para elaborar e monitorar o planejamento estratégico da empresa, enquanto que em uma MPE o mesmo profissional é o responsável por exercer se não todas, a maioria das atividades da empresa.

Souza et al. (2007) diz que devido possuir certas limitações inerentes ao padrão dos pequenos modelos de negócios as pequenas empresas não podem atuar diante de diferentes cenários simultaneamente, ou seja, as pequenas empresas devem verificar se suas ações vão otimizar os recursos investidos, seja os financeiros ou até mesmo a mão de obra. Para que a empresa alcance suas metas o planejamento estratégico deve mostrar de forma clara os recursos e ações que as MPE's deve executar para atingir seus objetivos. Esta ferramenta se torna crucial para os pequenos negócios pois se torna um diferencial para manter a prosperidade financeira e enfrentar algumas questões acerca do desequilíbrio financeiro.

O aumento no número de microempreendedores individual é bem expressivo cada dia mais as pessoas buscam por melhor de vida através do seu próprio negócio devido à dificuldade de encontrar emprego por isso eles tem um papel fundamental na geração de renda e até mesmo de emprego para outras pessoas. Com tudo para isto, é necessário a aplicação de um planejamento estratégico nestes pequenos negócios para fortalecer e fazer com que a empresa conquiste seu espaço no seu ramo de atuação e possa garantir a seu cliente um produto com qualidade e eficácia. Para Bethlem (2004), as estratégias e o planejamento, bem como, sua elaboração, execução, implantação, acompanhamento e controle devem ser ensinados e não somente aprendidos mais adotados como útil.

A falta de um planejamento para uma empresa pose ser fatal. De acordo com o Instituto Brasileiro de Geografia e Estatística (IBGE, 2003), de cada dez empresas, um total de seis fecha antes de completar 5 anos, 
isto representa um total de mais de $50 \%$. Isso ocorre devido à falta de conhecimento dos empreendedores sobre a importância de um planejamento estratégico e de um planejamento. O Planejamento não exclui todos os riscos que uma empresa pode passar, mas auxilia os gestores na identificação dos problemas e qual a melhor maneira para solucionar os mesmos, antes de ocorrer danos à empresa, o planejamento possibilita evitar estas dificuldades (SANTOS, 2010).

O planejamento estratégico traz para as empresas resultados importantes e significativos, entretanto a maioria das MPE's não adotam o uso desta ferramenta, o que acarreta em uma má utilização dos recursos disponíveis, perda de aterias, de clientes e também perdas financeiras. Para vários pequenos empresários o plano estratégico é uma questão bastante técnica e que não demostra resultados para seu negócio, além de exigir tempo, devido a isto eles acabam não utilizando o planejamento estratégico (GODOY, 2009, citado por OLIVEIRA et al., 2011).

Apesar de ser indispensável, o planejamento estratégico para o pequeno empreendedor é uma ferramenta que não é utilizada, porém ela é de extrema importância, assim como um planejamento simples, o plano estratégico mostra o caminho, os recursos, ações e os passos que devem ser feitos para que o empreendimento tenha resultados positivos. Ele traz consigo um leque de maneiras bem estruturadas que auxiliam ao microempreendedor na tomada de decisão.

Portanto, o planejamento estratégico se mostra uma ferramenta que deve ser utilizada por todo empreendedor, apesar das MPE's não a adotarem para seu negócio, é certo que sua funcionalidade traz benefícios e resultados para empresa. As micro e pequenas empresas é um segmento que cresce consideravelmente no Brasil, e cabe aos novos empreendedores entender e se adaptar a esta ferramenta para que os mesmos possam obter melhores resultados para o seu negócio, e proporcionar qualidade nos produtos e serviços para com o seu cliente.

\section{CONCLUSÕES}

Esse artigo buscou mostrar o quanto o planejamento estratégico é uma ferramenta que serve ao microempreendedor e o quanto ela é importante para as MPE's pois ela mostra como o gestor do pequeno negócio pode desenvolver e melhorar suas atividades dentro da empresa buscando cada vez mais se destacar e elevar os serviços ofertados para os seus clientes.

Em relevância o estudo ajudará as pessoas a se planejar estrategicamente diante do mercado e a se sobressair de seus concorrentes ganhando mais e mais espaço no seu ramo de atuação. Apesar das MPE's não utilizar o planejamento estratégico ele se torna um meio eficiente e eficaz de fazer com que os pequenos negócios tenham a oportunidade de crescer e se manter, basta apenas adotar o uso do plano estratégico, aprender a usá-lo e entender como ele funciona para enfim as pequenas empresas alcançaram melhores resultados.

\section{REFERÊNCIAS}


2004.

CAVAlCANTE, F. A.. Planejamento estratégico participativo. Concepção, implementação e controle de estratégias. São Paulo: Senac, 2008.

CERVO, A. L.; BERVIAN, P. A.. Metodologia cientifica. 5 ed. São Paulo: Prentice Hall, 2002.

CHIAVENATO, I.. Introdução à teoria geral da administração: na administração das organizações. 3 ed. Rio de Janeiro: Elsevier, 2004.

CHIAVENATO, I.. Planejamento estratégico. 2 ed. Rio de Janeiro: Elsevier, 2010.

CHIAVENATO, I.. Planejamento estratégico. 8 ed. Rio de Janeiro: Elsevier, 2003.

DORNELAS, J. C. A.. Plano de negócios: o segredo do sucesso do empreendedor. Mito ou realidade. 2010.

GIL, A. C.. Como elaborar projetos de pesquisa. São Paulo: Atlas, 2010.

IBGE. Instituto Brasileiro de Geografia e Estatística. As micros e Pequenas Empresas Comerciais e de Serviços no Brasil. Estudos e Pesquisas Informação Econômica. Rio de Janeiro, 2003.

KOTLER, P.. Administração de marketing: a edição do novo milênio. São Paulo: Pretence Hall, 2000.
MARCONI, M.; LAKATOS, E. M.. Fundamentos de metodologia cientifica. São Paulo: Atlas, 2010.

MAXIMIANO, A. C. A.. Introdução à administração. 6 ed. São Paulo: Atlas, 2008.

MINTZBERG, H.; QUINN, J. B.. O processo da estratégia. Porto Alegre: Brookman, 2001.

MINAYO, M. C. S.. Pesquisa social: teoria, método e criatividade. Petrópolis: Vozes, 2001.

OLIVEIRA, L. R.; RIBEIRO, J. L. D.. Planejamento estratégico aplicado a uma pequena empresa de desenvolvimento de software. Porto Alegre: UFRGS, 2011.

PEREIRA, M.. Planejamento: teorias e modelos. Florianópolis: UFSC, 2008.

SANTOS, A.. A importância do Planejamento estratégico de micro, pequeno e médio portes. Monografia (Graduação em Gestão Empresarial) - Universidade Cândido Mendes, Rio de Janeiro, 2010.

SILVEIRA, H. S.. In Inteligência organizacional e competência. Brasília: UNB, 2001.

SOUZA, W.; QUALHARINI, E.. O planejamento estratégico nas micro e pequenas empresas. In: WORKSHOP GESTÃO INTEGRADA: RISCOS E DESAFIOS, 3. Anais. São Paulo: Centro Universitário SENPC, 2007.

A CBPC - Companhia Brasileira de Produção Científica (CNPJ: 11.221.422/0001-03) detém os direitos materiais desta publicação. Os direitos referem-se à publicação do trabalho em qualquer parte do mundo, incluindo os direitos às renovações, expansões e disseminações da contribuição, bem como outros direitos subsidiários. Todos os trabalhos publicados eletronicamente poderão posteriormente ser publicados em coletâneas impressas sob coordenação da Sustenere Publishing, da Companhia Brasileira de Produção Científica e seus parceiros autorizados. Os (as) autores (as) preservam os direitos autorais, mas não têm permissão para a publicação da contribuição em outro meio, impresso ou digital, em português ou em tradução. 